\title{
APPLICATION OF RATING SCALE MODEL IN CONVERSION OF RATING SCALES' POINTS TO THE FORM OF TRIANGULAR FUZZY NUMBERS
}

Bartłomiej Jefmański, Ph.D.

Wroctaw University of Economics

Faculty of Economics, Management and Tourism

Department of Econometrics and Computer Science

Nowowiejska 3, 58-500 Jelenia Góra, Poland

e-mail: bartlomiej.jefmanski@ue.wroc.pl

Received 5 July 2014, Accepted 1 December 2014

\begin{abstract}
A new application of fuzzy sets theory in social and economic research is a fuzzy measurement of respondents' opinions. In the subject literature fuzzy rating scales or fuzzy conversion scales are being applied. In this second case, a key stage is a choice of such parameters' values of fuzzy numbers which will best illustrate the perception of linguistic values constituting points of measurement scales.

In the construction of fuzzy conversion scales the item response theory models can find an application. The transformation method of verbal categories to the form of triangular fuzzy numbers with the application of rating scale model was proposed in this article. Usefulness of a suggested approach was introduced on the basis of the analysis of selected research results on inhabitants' quality of life in one of the Lower Silesian Voivodship districts. The analysis results showed big ambiguity of particular verbal categories and, in consequence, the validity of fuzzy conversion scales application.
\end{abstract}

Keywords: fuzzy conversion scales, fuzzy numbers, rating scale model.

JEL classification: C01, C38, C51, D70. 


\section{Introduction}

Rating scales, where particular scale's points constitute verbal categories (so called linguistic values), are used to rate respondents' opinions. Due to the fact that the conceptual meaning of these categories may be different for respondents, they become a source of ambiguity. . A way to consider this ambiguity can be by expressing verbal categories in the form of fuzzy numbers. In order to do that, there is a possibility to apply an approach based on fuzzy rating scales and on fuzzy conversion scales ${ }^{1}$. The first of these assumes the use of fuzzy rating scales at the stage of measurement tool construction. In the second case we deal with the results conversion of classical measurement done by rating scales to the form of fuzzy numbers.

The method suggested in this article is included in the second approach and consists in the transformation's measurement results of respondents' opinions to the form of triangular fuzzy number with an application of one model of item response theory (IRT), described as rating scale model (RSM). It enables us to include, at the stage of the measurement results analysis of respondents' opinions, ambiguity of verbal categories, constituting rating scale points. This method will be characterized on the basis of an analysis of selected results of quality of life of inhabitants of one of the Lower Silesian Voivodships districts.

\section{Rating scale points as triangular fuzzy numbers}

Fuzzy sets theory is a generalization of the classical sets theory. This generalization means that in a classical variant elements belong to a particular set or not. However, in the case of fuzzy sets there is a possibility of partial elements' membership in a set ${ }^{2}$. In marketing research the fuzzy sets theory supports vagueness and ambiguity concepts, which are connected with subjective respondents' statements. It enables a conversion of verbal categories constituting rating scale points to the form of fuzzy numbers.

A fuzzy number is a fuzzy set $\widetilde{A} \subseteq R$, described in a set of real numbers and fulfilling the following conditions ${ }^{3}$ :

$-\widetilde{A}$ is a normalized set,

- $\widetilde{A}$ is a convex set,

- membership function of set $\widetilde{A}$ is a piecewise continuous function.

The shape of a fuzzy number depends on its membership function. Membership function for a triangular fuzzy number has the following form: 


$$
\mu(x)=\left\{\begin{array}{l}
\frac{x-a_{1}}{a_{2}-a_{1}}, a_{1}<x<a_{2} \\
\frac{a_{3}-x}{a_{2}-a_{3}}, a_{2}<x<a_{3} \\
0 \text { for } x \leq a_{1} \text { or } x \geq a_{3} \\
1 \quad \text { for } x=a_{2}
\end{array}\right.
$$

Graphical form of the triangular fuzzy number $\widetilde{A}$ illustrates Figure 1 .

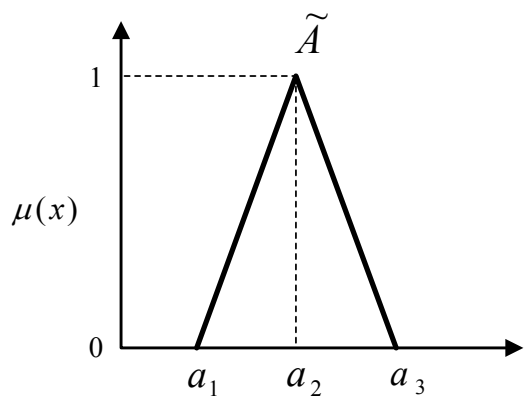

Fig. 1. Graphical interpretation of triangular fuzzy number Source: own study.

The triangular fuzzy number is described by three parameters: $\alpha_{1}, \alpha_{2}, \alpha_{3}$. Parameters $\alpha_{1}$ and $\alpha_{3}$ are adequately left and right spreads of the fuzzy number. The parameter $\alpha_{2}$ represents such a real number, for which membership function value equals 1 . Triangular fuzzy numbers are most often applied to convert verbal categories. The examples of such conversions can be found among others in the studies of: Chien and Tsai ${ }^{4}$, Liu et al. ${ }^{5}$, Carrasco et al. ${ }^{6}$, Erdoğan et al. ${ }^{7}$, Charles et al. ${ }^{8}$, Farkhondezadeh et al. ${ }^{9}$. Conversion requires determining three out of the above outlined parameters of a triangular fuzzy number for each category. A review of works in the context of the way of establishing fuzzy numbers parameters for verbal categories was introduced in Jefmański's study ${ }^{10}$.

\section{Application of RSM model in determining triangular fuzzy numbers parameters}

IRT models constitute an alternative for a classical measurement theory. They allow to explain a mechanism being the underlying reason for answering by the respondent to the scale items, both from the viewpoint of the scale attribute, as well as the characteristics of 
the respondents associated with the phenomenon that is being measured. (e.g. competences, emotional engagement etc. $)^{11}$. A detailed characteristics of IRT models can be found among others in the studies of: Hambleton et al. ${ }^{12}$, Embretson and Reise ${ }^{13}$, Ostini and Nering ${ }^{14}$, DeMars ${ }^{15}$.

One of the best-known IRT models is a rating scale model. It was suggested by Georg Rasch $^{16}$ and then developed by David Andrich ${ }^{17}$. The model makes it possible to estimate the probability of selecting a particular category by a respondent in the evaluation of the selected scale item. This probability depends on item difficulty, respondent's ability and threshold for a particular category. In accordance with RSM model, the probability of choosing the category $x$ on the $i$-th position by the $n$-th respondent is introduced by the following equation ${ }^{18}$ :

$$
\pi_{\ddot{u}}=\frac{\ddot{\mathrm{u}} \sum_{j=0}^{x}\left[\beta_{\ddot{u}}-(\delta+\tau)\right]}{\sum_{k=0}^{m} \ddot{\mathrm{u}} \sum_{j=0}^{k}\left[\beta_{\ddot{u}}-(\delta+\tau)\right]}
$$

where:

$\beta_{n}-$ an ability level of $n$-th respondent to give appropriate answer on item $i$,

$\delta_{i}$ - difficulty of the item $i$,

$\tau_{j}-$ threshold for $j$-th category within $i$-th item.

The presented model allows us to transform measurement results from an ordinal scale into the interval one. However, it does not find an application in an analysis of extreme answers patterns on item positions (e.g. when a respondent chooses "extreme" categories for example "very low" or "very high" within all items). An advantage of this model is that parameters concerning the respondent and the item are expressed by a common measurement unit called logit, on the same continuum. One should also emphasise that its application requires to accept a unidimensionality assumption (all items measure only one latent variable), and local independence of items (an answer for a certain scale item is independent from an answer for other propositions).

The most important RSM model's parameters, from the view of converting verbal categories to the form of triangular fuzzy numbers, are threshold values for these categories. Threshold values are outlined on the continuum of a latent variable at the intersection point of the characteristic curves of adjacent categories. Then the threshold value constitutes a point where the probability of selecting one of the two adjacent categories by the respondent is the same and equals $50 \%$. A detailed characteristics of threshold values in IRT models, together 
with a graphical presentation, is included in Linacre's study ${ }^{19}$. The method suggested in this article assumes determining the areas of triangular fuzzy numbers ranges for the categories that are organised in accordance with the threshold values corresponding to these categories. In Table 1 formulas are introduced that allow to establish the parameters of triangular fuzzy numbers for each of these categories outline within $i$-th item. An example concerns a rating scale with five ordering verbal categories, properly appointed: very low (VL), low (L), medium (M), high (H), very high (VH).

Table 1. Formulas to assess parameters of triangular fuzzy numbers for verbal categories

\begin{tabular}{|c|c|c|c|}
\hline \multirow{2}{*}{ Category } & \multicolumn{3}{|c|}{ Parameters of triangular fuzzy numbers } \\
\cline { 2 - 4 } & $\alpha_{1}$ & $\alpha_{2}$ & $\alpha_{3}$ \\
\hline $\mathrm{VL}$ & -4 & -4 & $\tau_{i 1}$ \\
\hline $\mathrm{L}$ & $\tau_{i 1}$ & $\frac{\tau_{i 1}+\tau_{i 2}}{2}$ & $\tau_{i 2}$ \\
\hline $\mathrm{M}$ & $\tau_{i 2}$ & $\frac{\tau_{i 2}+\tau_{i 3}}{2}$ & $\tau_{i 3}$ \\
\hline $\mathrm{H}$ & $\tau_{i 3}$ & $\frac{\tau_{i 3}+\tau_{i 4}}{2}$ & $\tau_{i 4}$ \\
\hline $\mathrm{VH}$ & $\tau_{i 4}$ & 4 & 4 \\
\hline
\end{tabular}

Source: own study.

It is easy to notice that in a suggested approach two out of three parameters of fuzzy numbers assigned to extreme categories are arbitrarily determined. These are parameters $a_{1}$ and $a_{2}$, in the case of the first category, and $a_{2}$ and $\mathrm{a}_{3}$ in the case of the last category. It results from the fact that in the RSM model the continuum of a latent variable is most often limited from the left side of value -3 or -4 . Right-sided limitation is usually in point 3 or 4 . In this paper, it is suggested that the values of parameters $a_{1}$ and $a_{2}$ of a fuzzy number assigned to the least favourable category should be set at level -4 . In the case of the parameters $a_{2}$ and $a_{3}$ of a fuzzy number assigned to the most beneficial category, values on level 4 were established. It is characteristic for the RSM model that threshold values for particular categories can differ within particular items. It means that the approach proposed in this article requires assessing the parameters of fuzzy numbers separately for each item. 


\section{Empirical example}

The proposed method was applied in the analysis of data gathered under research conducted in a crossborder area including two districts: on the Polish side -the district of Zgorzelec and on a German one (Saxon) - the district of Goerlitz. The research was a part of Polish-German project titled "Quality of life in a cross-border area - strengthening cross-border inflows for a common sustainable development and regional planning” and it was conducted using PAPI method (Paper and Pencil Interview) in the period from November 2012 to February 2013. 873 interviews were conducted. A choice of respondents was of purposeful character, including the population structure referring to sex, age, and place of residence. The usefulness of the proposed approach was presented on the example of the analysis of the results obtained from one of the applied subscales concerning inhabitants`satisfaction from a current professional situation. The subscale included 4 items:

P1 - currently job (its attractiveness, work conditions, work environment and atmosphere etc.),

P2 - employment security (transience, junk contracts etc.),

P3 - chances for finding a new attractive job,

P4 - keeping the right balance between work time and spare time.

In the evaluation of each subscale item, five ordered categories have been applied: very dissatisfied, dissatisfied, hard to say, satisfied, very satisfied. Moreover, let us assume the following interpretation of the RSM model's parameters in the context of respondents' satisfaction assessment ${ }^{20}$ :

$\theta_{i}$ - measurement of a respondent's satisfaction level reflecting all personal features which may influence the level of their satisfaction,

$\delta_{j}$ - parameter reflecting the ability of the $j$-th item in providing satisfaction to respondents.

The approach proposed in the article requires the assessment of five characteristic curves for verbal categories, within each of the four subscale items. The assessed characteristic curves were introduced in Figure 2. 
ICC plot for item P1

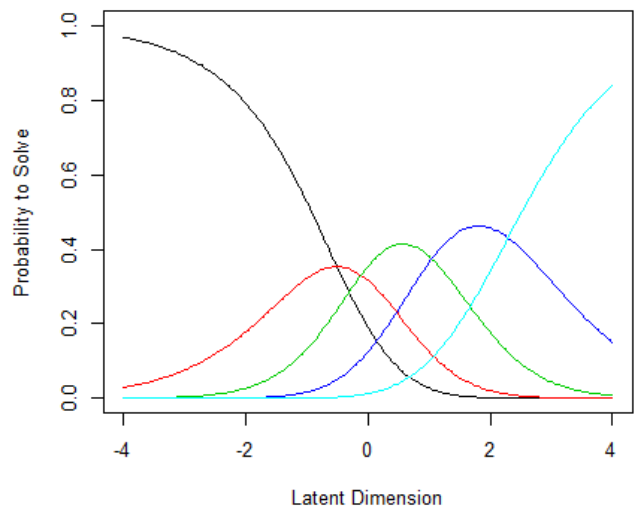

ICC plot for item P3

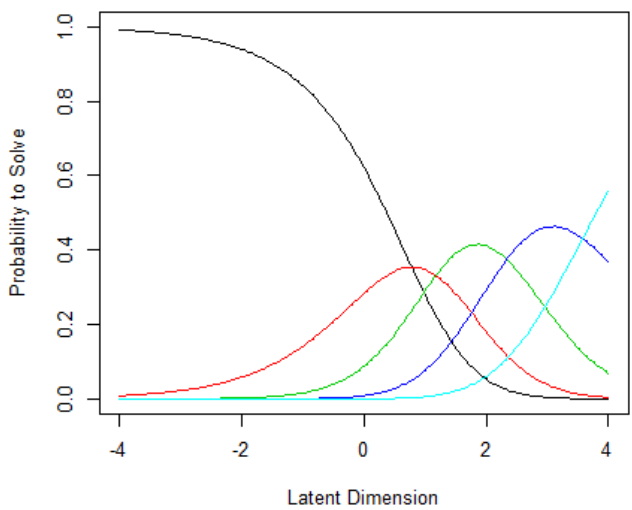

ICC plot for item P2

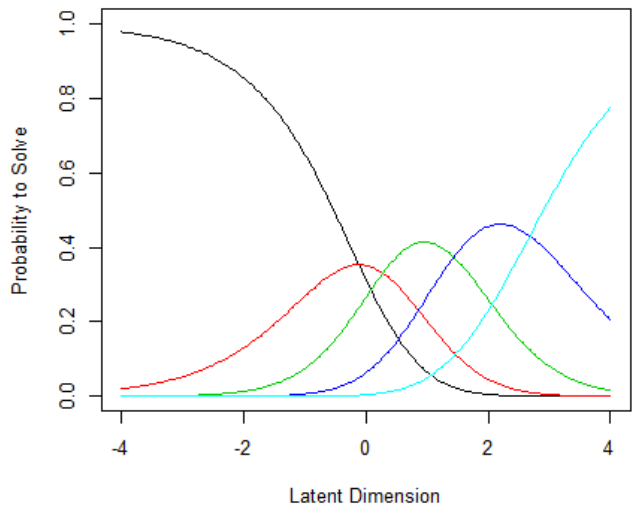

ICC plot for item P4

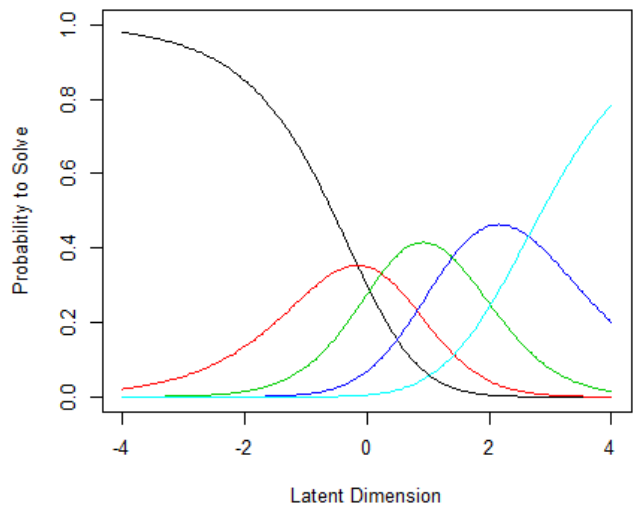

Fig. 2. Characteristic curves for four subscale's items

Source: own study with the application of eRm package of $\mathrm{R}$ programme.

Next, at the intersection point of the characteristic curves of adjacent verbal categories, the threshold values have been outlined (Table 2).

Table 2. Threshold values for categories within particulary subscale's item

\begin{tabular}{|c|c|c|c|c|}
\hline Item & $\tau_{1}$ & $\tau_{2}$ & $\tau_{3}$ & $\tau_{4}$ \\
\hline P1 & -0.508 & -0.114 & 1.046 & 2.288 \\
\hline P2 & -0.118 & 0.277 & 1.435 & 2.679 \\
\hline P3 & 0.783 & 1.177 & 2.336 & 3.579 \\
\hline P4 & -0.157 & 0.237 & 1.395 & 2.638 \\
\hline
\end{tabular}

Source: own calculations with the application of eRm package of $\mathrm{R}$ programme. 
It is characteristic of a proposed method that distances between threshold values of neighbouring categories are the same for all the subscale's items. Within the example, one has calculated the distance between threshold values $\tau_{3}$ and $\tau_{4}$ for the first subscale's item. This distance equals 1.24 and is the same for item no. 2, 3 and 4. The distance between threshold values $\tau_{2}$ and $\tau_{3}$ is also identical for all the subscale's items and equals 1.16.

Having the assessed threshold values, the parameters of triangular fuzzy numbers for each verbal category (separately for each subscale item) have been determined in accordance with the patterns listed in Table 1. The results of the assessed parameters are introduced in Table 3.

Table 3. Parameters of triangular fuzzy numbers assigned to verbal categories

\begin{tabular}{|c|c|c|c|c|c|}
\hline Item & Very dissatisfied & Dissatisfied & Hard to say & Satisfied & Very satisfied \\
\hline P1 & $(-4 ;-4 ;-0.508)$ & $(-0.508 ;-0.311 ;-0.114)$ & $(-0.114 ; 0.580 ; 1.046)$ & $(1.046 ; 1.667 ; 2.288)$ & $(2.288 ; 4 ; 4)$ \\
\hline P2 & $(-4 ;-4 ;-0.118)$ & $(-0.118 ; 0.079 ; 0.277)$ & $(0.277 ; 0.856 ; 1.435)$ & $(1.435 ; 2.057 ; 2.679)$ & $(2.679 ; 4 ; 4)$ \\
\hline P3 & $(-4 ;-4 ; 0.783)$ & $(0.783 ; 0.980 ; 1.177)$ & $(1.177 ; 1.757 ; 2.336)$ & $(2.336 ; 2.958 ; 3.579)$ & $(3.579 ; 4 ; 4)$ \\
\hline P4 & $(-4 ;-4 ;-0.157)$ & $(-0.157 ; 0.04 ; 0.237)$ & $(0.237 ; 0.816 ; 1.395)$ & $(1.395 ; 2.017 ; 2.638)$ & $(2.638 ; 4 ; 4)$ \\
\hline
\end{tabular}

Source: own calculations.

The graphical form of triangular fuzzy numbers assigned to verbal categories within four subscale's items was shown in Figure 3.

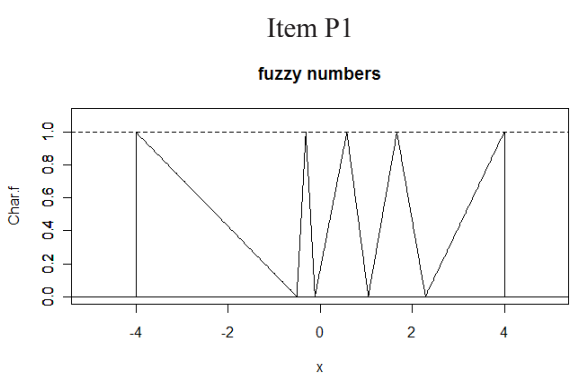

Item P3

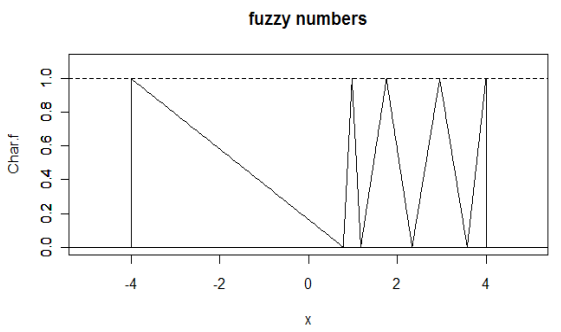

Item P2

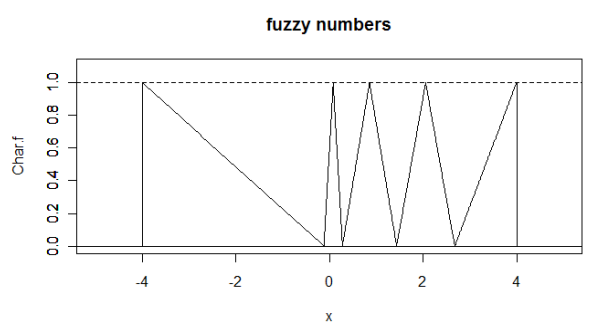

Item P4

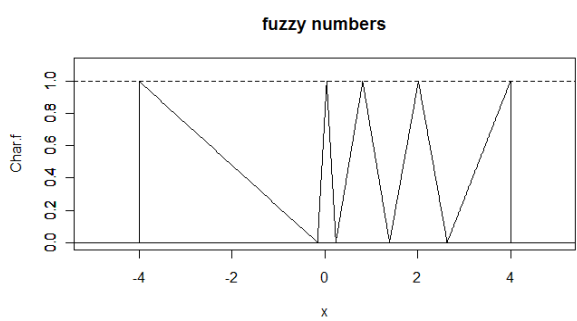

Fig. 3. Fuzzy numbers for subscale's item

Source: own study with the application of fuzzy OP package of R programme. 
The conversion of measurement results to the form of triangular fuzzy numbers depends on the transformation of the respondents' answers from the form of verbal categories into appropriate fuzzy numbers. An example of such conversion within two subscale's item, for data including answers of the first five respondents, was shown in Figure 4.

\begin{tabular}{|c|c|c|}
\hline Resp. & P1 & P2 \\
\hline 1 & 0 & 1 \\
\hline 2 & 1 & 3 \\
\hline 3 & 3 & 0 \\
\hline 4 & 2 & 1 \\
\hline 5 & 1 & 2 \\
\hline
\end{tabular}

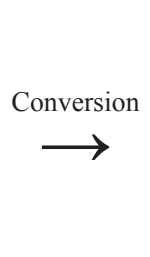

\begin{tabular}{|c|c|c|}
\hline Resp. & P1 & P2 \\
\hline 1 & $(-4 ;-4 ;-0.508)$ & $(-0.118 ; 0.079 ; 0.277)$ \\
\hline 2 & $(-0.508 ;-0.311 ;-0.114)$ & $(1.435 ; 2.057 ; 2.679)$ \\
\hline 3 & $(1.046 ; 1.667 ; 2.288)$ & $(-4 ;-4 ;-0.118)$ \\
\hline 4 & $(-0.114 ; 0.580 ; 1.046)$ & $(-0.118 ; 0.079 ; 0.277)$ \\
\hline 5 & $(-0.508 ;-0.311 ;-0.114)$ & $(0.277 ; 0.856 ; 1.435)$ \\
\hline
\end{tabular}

Fig. 4. The example of conversion of measurement results to the form of triangular fuzzy numbers Source: own study.

The general assessment of particular subscale's items was made through calculation of the arithmetic mean. One should emphasize that in accordance with the principles of arithmetics for fuzzy numbers an average assessment of a particular subscale's item also has a form of triangular fuzzy numbers. A formula which is used to calculate an average value of the triangular fuzzy number was introduced, for example in the study of Bojadziev and Bojadziev ${ }^{21}$. A graphical form of an average assessment of each item was introduced in Figure 5.

Item P1

fuzzy numbers

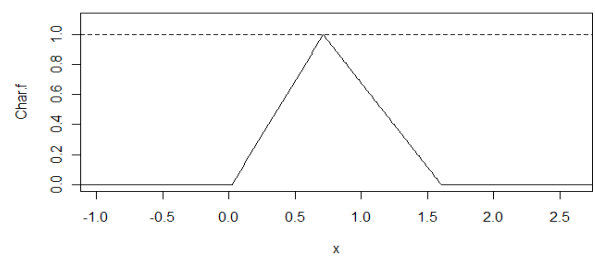

Item P3

fuzzy numbers

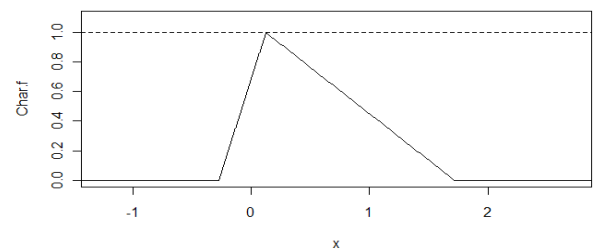

Item P2

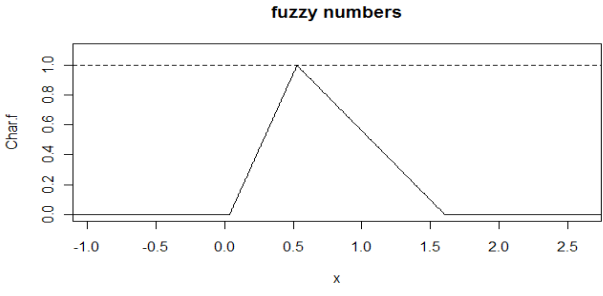

Item P4

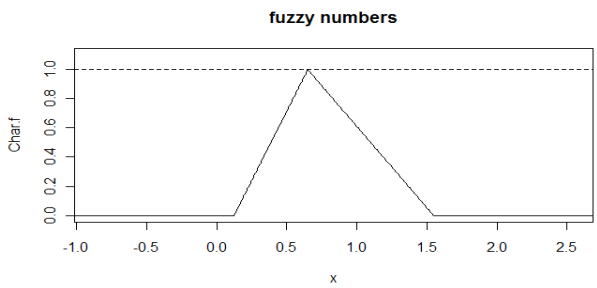

Fig. 5. Average assessments for subscale's item

Source: own study with the application of fuzzy OP package of R programme. 
In each of four cases, the ranges of fuzzy numbers are very similar to each other. Direct comparison of average assessments of subscale's items is impossible in this case, but defuzzification methods for fuzzy numbers can be applied here. Such a measure allows to transform average assessment to the single value from the set of real numbers. Further analyses are also possible with the application of statistical methods for fuzzy data (e.g. fuzzy regression analysis).

\section{Conclusions}

In this article, the proposed method of results measurement of respondents' analysis combines IRT theory with the fuzzy sets ones. The presented empirical example showed that, in particular verbal categories, the numbers spread is very diversified, which shows how ambiguously they are perceived by respondents. The inclusion of this ambiguity at the stage of the results analysis can be held by the use of transposed fuzzy scales. In such a scale construction one can apply the RSM model, which allows to assign an appropriate triangle fuzzy number to each verbal category. The bigger the spread of fuzzy numbers is, the less precise the verbal category appears.

The presented results of the proposed method application suggest that with high homogeneity of scale measurement the spreads of fuzzy numbers ordered to scale's categories are approximate within a particular scale item. In such a case, it is possible to adopt fuzzy numbers for particular categories that are common to all the scale items (e.g. through calculating arithmetic mean from fuzzy numbers).

It is also worth mentioning that in the case when average assessments of particular items will have a form of non-symmetric fuzzy numbers, then it is essential to select defuzzification methods of fuzzy numbers very carefully. A choice of defuzzification method can have an impact on the results of e.g. significance ranking of particular items. Dependency between defuzzification method and gained results should become a subject of a separate research.

The method proposed in this article constitutes an introduction to the issues about the possibilities of IRT models application in the transformation of verbal categories to the form of fuzzy numbers. In further research it is planned to apply other IRT models (e.g. the partial credit model) and compare the results with the ones gained thanks to the method mentioned in this article. The obtained measurement results will also be compared with the results of fuzzy rating scales. 


\section{Notes}

${ }^{1}$ de Sáa et al. (2013).

2 Kandel (1982).

${ }^{3}$ Zimmermann (2001).

${ }^{4}$ Chien, Tsai (2000).

${ }^{5}$ Liu et al. (2008).

${ }^{6}$ Carrasco et al. (2012).

${ }^{7}$ Erdoğan et al. (2013).

${ }^{8}$ Charles et al. (2013).

${ }^{9}$ Farkhondezadeh et al. (2013).

10 Jefmański (2011).

11 Sagan (2005).

${ }^{12}$ Hambleton et al. (1991).

13 Embretson, Reise (2000).

14 Ostini, Nering (2006).

${ }^{15}$ DeMars (2010).

16 Rasch (1960).

${ }^{17}$ Andrich (1978).

18 Ibidem.

19 Linacre (2010).

${ }^{20}$ Pagani, Zanarotti (2010).

${ }^{21}$ Bojadziev, Bojadziev (1995).

\section{References}

Andrich, D. (1978). A rating formulation for ordered response categories. Psychometrika, 43, 561-573. DOI: 10.1007/BF02293814.

Bojadziev, M. \& Bojadziev, G. (1995). Fuzzy Sets, Fuzzy Logic, Applications. Singapore: World Scientific Publishing.

Carrasco, R.A., Munoz-Leiva, F., Sánchez-Fernández, J. \& Liébana-Cabanillas, F.J. (2012). A model for the integration of e-financial services questionnaires with SERVQUAL scales under fuzzy linguistic modeling. Expert Systems with Applications, 39, 1535-1547. DOI: 10.1016/j.eswa.2012.03.055.

Charles, V., Kumar, M. \& Suggu, S. (2013). Adapting Fuzzy Linguistic Servqual Model: A Comparative Analysis of Bank Services. Middle-East Journal of Scientific Research, 18 (8), 1119-1132. DOI: http://dx.doi.org/10.7835/ccwp-2012-09-0008.

Chien, Ch.-J. \& Tsai, H.-H. (2000). Using fuzzy number to evaluate perceived service quality. Fuzzy Sets and Systems, 116 (2), 289-300. DOI: 10.1016/S0165-0114(98)00239-5. 
DeMars, Ch. (2010). Item Response Theory. Oxford: Oxford University Press.

de Sáa, S.R., Gil, M.Á., Garcia, M.T.L. \& Lubiano, M.A. (2013). Fuzzy Rating vs. Fuzzy Conversion Scales: An Empirical Comparison through the MSE. In: Synergies of Soft Computing and Statistics for Intelligent Data Analysis, eds. R. Kruse, M.R. Berthold, M. Moewes, M.A. Gil, P. Grzegorzewski, O. Hryniewicz (pp. 135-144). Berlin Heidelberg: Springer.

Embretson, S.E. \& Reise, S.P. (2000). Item Response Theory for Psychologists. Makwah: Lawrence Erlbaum Associates.

Erdoğan, M., Bilişik, Ö.N., Kaya, İ. \& Baraçh, H. (2013). A customer satisfaction model based on fuzzy TOPSIS and SERVQUAL methods. Lecture Notes in Management Science, 5, 74-83. DOI: 10.1080/14783363.2013.809942.

Farkhondezadeh, A., Rakhsha, S.H., Fek, M.R., Zarafshan, H., Cheramy, F. \& Yahdy, E. (2013). Identification and ranking of effective factors of marketing (controllable) to receive the services from free zone with MADM approach. European Online Journal of Natural and Social Sciences, 2 (3), 507-517.

Hambleton, R.K., Swaminathan, H. \& Rogers, H.J. (1991). Fundamentals of Item Response Theory. Newbury Park, CA: Sage Publications.

Jefmański, B. (2011). Nowe podejście w pomiarze opinii respondentów z zastosowaniem skal porządkowych i elementów teorii zbiorów rozmytych - charakterystyka wybranych aspektów metodologicznych. Prace Naukowe UE we Wrocławiu, 236, 184-191.

Kandel, A. (1982). Fuzzy techniques in pattern recognition. New York: John Wiley \& Sons.

Linacre, J.M. (2010). Transitional categories and usefully disordered thresholds. Online Educational Research Journal, 1-10.

Liu, X., Zeng, X., Xu, Y. \& Koehl, L. (2008). A fuzzy model of customer satisfaction index in e-commerce. Mathematics and Computers in Simulation, 77 (5-6), 512-521. DOI: 10.1016/j.matcom.2007.11.017.

Ostini, R. \& Nering, M. (2006). Polytomous Item Response Theory Models. Thousand Oaks: Sage Publications.

Pagani, L. \& Zanarotti, M.C. (2010). Some Uses of Rasch Models Parameters in Customer Satisfaction Data Analysis. Quality Technology \& Quantitative Management, 7 (1), 83-95.

Rasch, G. (1960). Probabilistic Models for Some Intelligence and Attainment Tests. Copenhagen: Danish Institute for Educational Research (Expanded edition, University of Chicago Press, 1980).

Sagan, A. (2005). Ocena ekwiwalencji skal pomiarowych w badaniach międzykulturowych. Zeszyty Naukowe Akademii Ekonomicznej w Krakowie, 659, 59-73.

Zimmermann, H.-J. (2001). Fuzzy set theory and its applications. Boston: Kluwer Academic Publishers. 